\title{
German Public Administration: Background and Key Issues
}

\author{
Sabine Kublmann, Isabella Proeller, Dieter Schimanke, \\ and Jan Ziekow
}

\section{Introduction: Background And Approach of the Publication}

In the international community of Public Administration (PA) of scholars and practitioners, there is a growing need to acquire knowledge and information, analysis, reviews and evaluations about Germany's administrative system and its recent reforms. The German system of public administration, which is embedded in the Rechtsstaat culture and deeply

S. Kuhlmann • I. Proeller

University of Potsdam, Potsdam, Germany

e-mail: skuhlman@uni-potsdam.de; proeller@uni-potsdam.de

D. Schimanke $(\bowtie)$

Ministry of Labour, Women, Health, Social Affairs of the German Land SaxonyAnhalt, Magdeburg, Germany

e-mail: Dieterschimanke@aol.com

J. Ziekow

German Research Institute for Public Administration, Speyer, Germany

e-mail: ziekow@foev-speyer.de

(C) The Author(s) 2021

S. Kuhlmann et al. (eds.), Public Administration in Germany, Governance and Public Management, https://doi.org/10.1007/978-3-030-53697-8_1 
rooted in the legalist tradition, is not simply regarded as a reference model for developing and transition countries. The basic features of the German administrative system have also inspired reform debates and modernisation efforts in OECD countries (Organisation for Economic Co-operation and Development). Due to its federal structure and the pronouncedly decentralised institutional setting, German public administration is regarded as a prime example of multilevel governance and strong local self-government. Furthermore, over the past decades, the traditional profile of the German administrative system has significantly been reshaped and remoulded through reforms, processes of modernisation and the transformation process in East Germany that began with unification. Wide-ranging approaches to reform from territorial amalgamations, privatisation and re-municipalisation, citizen participation, performance and human resource management, to better regulation and digital government, have been pursued at various levels of government and have had varying effects. Within this context, we observe an increasing interest in the academic and practitioner's community to acquire more comprehensive and systematic knowledge about Germany's administrative system, its institutional structures, functional responsibilities, civil service features, multilevel governance and most recent reforms. From a comparative public administration perspective, there is a need for more in-depth institutional knowledge concerning the various administrative systems in order to capture the peculiarities of different models, compare their strengths and weaknesses, and learn from each other while striving for improvement in public administration worldwide.

Against this background, it is a cause for concern and criticism that there has been no English language publication about German administrative systems on the market for about 20 years, when the German Section of the International Institute of Administrative Sciences (IIAS) published the last volume. A number of new topics, for example digital and open government, better regulation, co-production, participatory administration, have since come on the agenda and thus merit analytical attention. This book is about filling this knowledge gap. After two decades, it is time to present a topical, comprehensive yet differentiated analysis of Germany's public administration and its reforms that explicitly targets an international audience of PA practitioners, policy advisors, academics and students. The contributions in this book provide an overview of the key elements of German public administration at the federal, state (Länder) 
and local levels of government and of the current reform processes of the public sector. They focus, inter alia, on the following areas:

- key institutional features of public administration;

- changing relationships between public administration, society and the private sector;

- administrative reforms at different levels of the federal system; and

- new challenges and modernisation approaches, such as digitalisation, open government and better regulation.

The four topics are addressed in this book. Part I outlines the basic features, institutions and legal framework of German public administration at different levels of government and within its multilevel setting. In Part II, the relationship between politics and administration, administrative procedures, controlling and accountability mechanisms as well as key resources of administrative action (staff, finances) is analysed. The subsequent chapters focus on the various fields of administrative reform and modernisation, starting in Part III with reforms intended to reshape the macro-institutional setting of public administration. This includes a historical review of the administrative transformation after unification as well as more recent approaches to reform, such as the redrawing of territorial boundaries and jurisdictions, functional and structural reforms, the redefinition of the relationship between the public and the private sector through privatisation, and the opening up of public administration vis-àvis citizens and society. Finally, in Part IV, the focus is on changes in the distribution of responsibilities and resources within administrative organisations, the re-engineering of administrative processes, digital innovations and e-administration, the internal reorganisation of decision-making rules designed to enhance management capacities, efficiency in service delivery and the quality of policymaking.

\section{Part I: German Public Administration IN The Multilevel System}

Owing to its legalistic tradition, German public administration is very much rule-driven. Karl-Peter Sommermann refers to the concept of Rechtsstaat. German public administration is rooted in this tradition, which aims at the protection of human dignity and individual freedom by 
providing, alongside the principle of legality, the rules, principles and institutions that ensure the prevention of arbitrary state action and the protection of individual rights. A dynamic interpretation of the Basic Law (the German Constitution) of 1949 by the Federal Constitutional Court has constantly specified and extended the normative scope of fundamental rights, which are directly binding upon the legislative, executive and judicial powers. The constitutional principle of the welfare state has not only enhanced the dynamic evolution of the law, but also led to the creation of largely equivalent levels of infrastructure and services in the different territories of the federal state. The continually readjusted cooperation between the federal level and the Länder level and among the Länder themselves has strengthened the interoperability and coherence of their administrations, and competitive elements have fostered innovation.

The German federal architecture is shaped by a peculiar mix of strong decentralisation and a high degree of autonomy at lower levels of government, combined with an administrative culture of uniformity, solidarity and coordination. Nathalie Behnke and Sabine Kropp recapitulate the notion of this system as 'administrative federalism' to emphasise the prominent role of executives and administrations in policymaking and policy implementation. The dominant principle of administrative federalism is the territorial principle as opposed to the functional principle, that is governments and administrations at each level are responsible for all the tasks at this level with the exemption of special regulations for sectoral organisations. The federal level relies on the states (Lünder) for executing its tasks. For their part, the Länder executives have rights of co-decision in federal legislation via the Bundesrat (Federal Council). While formal jurisdictions are strongly decentralised, a dense web of interlocking powers as well as processes and institutions of coordination induce territorial governments to closely cooperate with each other when implementing (compulsory) joint tasks and coordinating autonomous responsibilities voluntarily. To date, German-style administrative federalism has been successful in curbing conflict caused by dissent among political parties and in implementing policies efficiently. However, trends like the upward shift of tasks from the Länder to the federal level and increasing party system fragmentation challenge its continued success and consequently require adaptation.

The three-tier system of German public administration is increasingly being brought in line with the overarching level of the European Union (EU) and in a special form of vertical arrangement. As Hans Hofmann 
calls it, the EU is a union of states suigeneris (unique). The Member States remain independent states and, in principle, retain their sovereignty. However, the EU's influence on national public administrations is constantly growing due to the increasing number of regulations (laws, bylaws, guidelines) and other EU programmes that require implementation in the Member States. The expanding influence of the EU is not limited to those areas where the Member States have transferred the authority to make laws to the EU, but is also spreading to those areas where the Member States have retained such authority. At the same time, however, there is no systematic codification of the law on administrative procedures at European level and no system of legal remedy for Union citizens equivalent to those at national level.

Germany's federal administration is significantly small in size (around ten per cent of all public employees). This special feature of the country's administrative system - as described by Julia Fleischer-is based on the division of responsibilities. The central (federal) level develops and adopts most of the public programmes and laws, and the state level (together with the local level) implements them. The administration at the federal level comprises the ministries, some subordinated agencies for special issues (e.g. the application of drugs, information security and the registration of refugees) and selected operational tasks in single administrative sectors (e.g. foreign affairs, the armed forces, the federal police and the supreme courts). The capacities to prepare and monitor laws are well developed. Moreover, the approaches to innovation and the instruments and tools of internal communication and coordination are exemplary compared to other countries.

According to the Basic Law, the states are, in principle, responsible for public administration, regardless of whether state or federal law is being enforced. The Federation has no authority to enforce state laws. When federal states carry out federal laws, they may do so in their own right or on federal commission. In both cases, the Federation has rights of supervision. Hans-Heinrich von Knobloch clearly makes these principles explicit on the relevant case of the portfolio of the Ministry of Interior. The Basic Law has set a narrow framework for the federal administration. The obligations and options of the federal administration are defined in full. However, superior federal authorities responsible for the entire federal territory may be established by law and passed with the consent of the Bundesrat for matters on which the Federation has the power to legislate. 
The institutions of the social security system are the main providers of services of the welfare state and cover a large share of the public budgets (about 45 per cent of expenditures). On the one hand, the system enjoys a certain degree of autonomy and is therefore called 'indirect state administration', as explained by Dieter Schimanke. On the other hand, the steering by federal legislation is quite extensive. However, in implementing this legislation, the institutions are only subject to limited state supervision, which is restricted to legal supervision (Rechtsaufsicht). Moreover, the social security institutions can appeal to the 'social courts' against the orders of the supervising state administration.

In Germany's federal system, the administrations of the 16 federal states (Länder) have central responsibility for the enforcement of both federal and state law. Ludger Schrapper observes that notwithstanding the heterogeneity in terms of their size, administrative tradition and culture, there is relative uniformity in their administrative structures (with the exception of the three city-states). Everywhere, the municipalities, which are part of the state executive under state law, play a significant and, above all, independent role as bodies of public administration. Still, there are some differences which are due to whether the administrations of the Länder have a two-tier or a three-tier structure. Within these varying structures, administration seems to be relatively homogeneous, not least because of the very similar staffing structures, career patterns and administrative cultures. Structural reforms of very different scope have been a long-term phenomenon since the 1990s.

The local level, also called the communal level (municipalities, cities and counties), plays a strong administrative and political role in the German system. Kay Ruge and Klaus Ritgen demonstrate the weight of the communal level in the figures for personnel and budgets. The right to local self-government is guaranteed in the Basic Law and has a long history. Moreover, the communal administration-and especially the county level-serves a second function. It is, in principle, the operational level responsible for implementing the programmes and laws of the federal and state levels. The local authorities mainly differentiate themselves from the federal and regional authorities by the mandates of their elected representative bodies (city council, county council and municipal council). The head of a local administration (mayor or county commissioner) is usually directly elected by the citizens. Finally, the principle of German local self-government and administration is a good 
example for practising the cornerstones of the European Charter of Local Self-Government.

\section{Part II: Politics, Procedures and Resources}

The relationship between politics and administration is the key to understand the conditions and interactions between administrations. In their chapter, Werner Jann and Sylvia Veit examine the relationships between politicians and administrators in Germany, both in institutional and legal terms as well as at all three levels of German executive federalism, that is the federal, state and local level. Using the concept of politicisation, they start with the distinction between politicians and civil servants and the viability of such distinction in practice. The central indicators are party membership and turnover rates after elections. Jann and Veit examine different dimensions of politicisation both in federal ministries and in the federal states, focusing on typical career patterns as well as the key features of the political-administrative relations at the local level. As a result, the authors identify a high degree of functional politicisation of top positions in public administration.

The dimension of public administration as a 'working state' was introduced into German administrative science as far back as the nineteenth century (von Stein 1870, p. 7). Taking a process-oriented approach, Jan Ziekow examines public administration as the interconnection of information, communications, interactions and decisions. As regards German administration, he assumes a distinction between processes and procedures, whereby one feature of these procedures vis-à-vis persons outside the administration is a high degree of juridification by administrative procedure law. He classifies and analyses the administrative processes according to different criteria and empirical and legal categories. Among other things, Ziekow deals with service delivery processes, communication, transparency and information, administrative procedure law, management processes, knowledge management, inter-organisational cooperation and administrative oversight.

In order to hold public administration accountable, a differentiated set of instruments is required. Veith Mehde emphasises-from a legal point of view-that the concept of accountability is an element of democratic legitimacy. He describes two very different mechanisms. First, the control exercised over the administrative jurisdiction and second, the control exercised by the courts of audit. He particularly emphasises the fact that it is 
not the role of the administrative courts and courts of audit to hold administration accountable. Rather, their role is to provide other actorsthe parliaments, the public, the media, etc.- the opportunity to hold the respective administration accountable. As part of their role in exercising administrative jurisdiction, Mehde describes the structure of administrative courts in Germany, the types of their decisions and the depth and extent of their control. He also describes the organisation and scope of review of the courts of audit as well as the effects of their control.

The professionalisation of public service staff is one of the most important aspects of efficient administration. The employment structure and training of these employees is generally characteristic of a national administrative system. Accordingly, Christoph Reichard and Eckhard Schröter open their chapter on civil service and public employment with the question, 'What kind of an animal is the German civil service?' Their contribution sheds light on the size and structure of public employment in Germany prior to presenting the two different types of employment status in the public service, 'civil servants' on the one hand and 'public employees' on the other. Following an overview of the legal framework and policies relating to the civil service, subsequent sections deal with recruitment and qualifications, compensation schemes and benefits as well as major reform trends.

'Money makes the world go round'-this also applies to public administration. Revenues and expenditures are central to public administration processes. In the chapter on public finance, Gisela Färber deals with the principles of budgeting and the budget cycle as well as the generation and distribution of tax revenues in Germany. In the latter context, she addresses, inter alia, the constitutional regulations on the distribution of financial resources and the structure of public expenditure and revenueproviding a general structural analysis as well as a breakdown of tax revenues from a federal perspective. Fürber goes on to discuss the considerable importance in the German federal financial system of the vertical and horizontal fiscal equalisation between the various administrative units. The chapter closes with an account of public indebtedness and budget deficits in Germany at different government levels. 


\section{Part III: Redrawing Structures, Boundaries and Service Delivery}

In order to understand more recent developments and modernisation efforts in the German administrative system, it is important to consider earlier developments, especially after reunification, which sharply distinguish the German case from other European countries. Against this backdrop, the chapter by Hellmut Wollmann reviews the transformation of public administration in East Germany following unification. He focuses on the process and result of the administrative transformation process in East Germany as one of the most comprehensive institutional shifts of the last century. He provides an overview of the peculiarities of the East German mode of transformation (as opposed to other transition countries) and of the 'transfer of institutions' from West to East. In trying to answer the question 'what shapes institutions', he analyses the drivers and triggers of the process as well as the impacts and outcomes of the transformation process achieved so far. Wollmann also reviews some remaining problems, legacies and new challenges facing the unified German administration.

Due to the highly decentralised federal structure and the allocation of administrative tasks primarily to sub-national units, reforms in the multilevel system have always played a key role in Germany. Sabine Kublmann and Jörg Bogumil analyse recent territorial, functional and structural reforms in the German Länder, which represent three of the most crucial reform trajectories at the sub-national level to date. The chapter sheds light on the variety of reform approaches pursued by the different Länder and also highlights some of the factors that account for these differences. Kublmann and Bogumil also address the transfer of state functions to local governments, the restructuring of Länder administrations (e.g. the abolishment of the meso level of Länder administrations and of single-purpose state agencies), and the redrawing of territorial boundaries at county and municipal levels. In the final section, they give a brief review of the recently failed (territorial) reforms in Eastern Germany.

Administrative reforms not only refer to vertical rescaling of competencies and tasks between levels of government but also to horizontal reorganisations vis-à-vis the private sector on the one hand, and in relation to citizens and society on the other. The chapter by Benjamin Friedländer, Manfred Röber and Christina Schaefer begins with the observation that in recent decades, the provision of public services in Germany has 
increasingly been transferred to bodies outside the core administration, which has changed the institutional landscape significantly. The authors examine four dominant institutional trends, namely corporatisation, outsourcing, privatisation and re-municipalisation. They also discuss some of the advantages and disadvantages of public vs. private service provision.

As regards the changing relationship between public administration and citizens/society, two major reform approaches merit attention. First, the co-production of services and the involvement of multiple actors, both in the delivery of services and in decision-making. The trend towards a more participatory administration and co-production with citizens is analysed by Stephan Grohs who specifically focuses on the shift from 'traditional' modes of service delivery and decision-making to co-producing features and participatory elements. He also addresses some of the resulting key problems and pitfalls, such as accountability, transparency and legitimacy.

\section{Part IV: Modernising Processes and Enhancing Management Capacities}

The fourth part of this book provides an analysis of the reform and modernisation efforts of German public administration, most of which target various internal administrative management capacities. As elsewhere, digitalisation is a ubiquitous and omnipresent organisational challenge for public administrations in Germany. In the chapter on digital transformation, Ines Mergel analyses how Germany is managing the transformation of its service delivery structures. She describes how the digital transformation of the public sector is embedded in a large-scale reform to digitalise the service delivery of 575 public services by 2022. Mergel also describes the legal basis of digital transformation with its centralised and decentralised organisational embeddedness of administrative responsibilities, and illustrates recent developments with selected cases of implementation.

Second, there has been a significant trend towards 'open government', which Jan Porth, Friederike Bickmann, Patrick Schweizer and Zarina Feller see as a trend towards greater openness in political and administrative actions. They provide a brief overview of the conceptual understanding of open government, the potential advantages and disadvantages as well as recent developments at the federal level of government in Germany. Three 
selected sub-fields of open government, namely open government data, open innovation and open budget, are presented in more detail.

The role of public administration is not only limited to service delivery but also extends into the legislative process and its involvement in drawing up and drafting new regulations. Sylvia Veit and Sabine Kublmann explore and describe how 'Better Regulation' has become an influential and established mechanism at the federal level and-in some cases-also at the Länder level in Germany. The authors introduce the basic features of the legislative process at the federal level in Germany, address different aspects of Better Regulation and outline the role of the National Regulatory Control Council (Nationaler Normenkontrollrat-NKR) as a 'watchdog' for compliance costs, red tape and regulatory impacts.

Public administration-not only in Germany-requires a sufficient number of qualified and motivated staff to produce services and implement policies efficiently, effectively, professionally and reliably. Hence, managing the workforce is one of the most crucial functions in public administration. The chapter by Isabella Proeller and John Siegel first examines the practices and developments in (core) human resource management (functions). They then turn to a discussion on the importance of leadership, performance-related pay, public service motivation and diversity management. The authors conclude by highlighting some of the major paradoxes of German public human resource management (HRM) in light of current challenges, such as demographic change, digital transformation and capabilities for organisational development.

In the final chapter, Isabella Proeller and John Siegel analyse two very prominent public management reform trajectories in German public administration over the past three decades since unification. In the 1990s, the New Steering Model emerged as a German variant of the New Public Management (NPM). Since the mid-2000s, local governments in Germany have been subjected to a mandatory reform of their budgeting and accounting system known as the New Municipal Financial Management reforms. These reforms have led to substantial changes, but have really only scratched the surface in terms of changing control mechanisms and the organisational culture. 


\section{International Context And Lessons to Learn}

Each of the chapters highlights and explains selected key features of the German administrative system or relevant approaches to reform, then provides descriptive information about these issues before moving on to problem-oriented analyses of the subject area. At the same time, these analyses are linked to key debates and theories in public administration and policy and are accessible and comprehensible to an international readership not familiar with the German case. Finally, each chapter draws some lessons and conclusions to be considered by international readers when it comes to concept transfer, good practice learning and institutional translations into different national contexts.

The book is designed to serve as a basic reference book for students, academics and practitioners interested in better understanding and contextualising German public administration. It elaborates on the particularities in order to make these understandable to an international readership. To this end, the authors embed their analyses in the international context and refer to formal as well as informal mechanisms and standard operating procedures at work, showing how they differ from other national systems and administrative settings elsewhere. 'Comparing is human' (Raadschelders 2011, p. 831ff.) because it helps to understand one's own (national) administrative system by comparing it with others and recognising its particularities, advantages and disadvantages, strengths and weaknesses (Kuhlmann and Wollmann 2019, p. 2). The aim is thus to stimulate the interest and curiosity of academics and practitioners in the variety of administrative systems beyond national borders and from a trans-European and global perspective.

Furthermore, to encourage international comparisons, each chapter in this book concludes with a 'lessons learned' section. These lessons point out important features and mechanisms that manifest themselves in the German setting and should be considered when referring to the German model in the international debate. For academics, lessons learned might point to the importance/non-importance of certain independent or contextual variables. For practitioners, lessons learned might point to caveats in concept transfer. For both communities, the different chapters may be helpful for a more thorough and informed comparison of the German case. 


\section{REFERENCES}

Kuhlmann, S., \& Wollmann, H. (2019). Introduction to Comparative Public Administration. Administrative Systems and Reforms in Europe (2nd ed.). Cheltenham/Northampton: Edward Elgar.

Raadschelders, J. C. N. (2011). Commentary-Between 'Thick Description' and Large-N Studies. The Fragmentation of Comparative Research. Public Administration Review, 71(6), 831-833.

von Stein, L. (1870 [2010]). Handbuch der Verwaltungslehre und des Verwaltungsrechts, Stuttgart: Cotta (reprint U. Schliesky (Ed.)).

Tübingen: Mohr.

Open Access This chapter is licensed under the terms of the Creative Commons Attribution 4.0 International License (http://creativecommons.org/licenses/ by $/ 4.0 /$ ), which permits use, sharing, adaptation, distribution and reproduction in any medium or format, as long as you give appropriate credit to the original author(s) and the source, provide a link to the Creative Commons licence and indicate if changes were made.

The images or other third party material in this chapter are included in the chapter's Creative Commons licence, unless indicated otherwise in a credit line to the material. If material is not included in the chapter's Creative Commons licence and your intended use is not permitted by statutory regulation or exceeds the permitted use, you will need to obtain permission directly from the copyright holder.

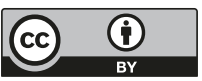

